\title{
An Analysis of Anthropometric Measurements of Children Enrolled in Programs for Managing Acute Malnutrition, in Kwale County, Kenya
}

\section{Z. Kralova (Zuzana Kralova)'1 D. Jakubcova (Denisa Jakubcova)', V. O. Okech (Victor Otieno Okech)², A. Ondrusova (Adriana Ondrusova) $)^{1,3}$}

${ }^{1}$ Trnava University in Trnava, Faculty of Health Care and Social

Work, Slovakia.

${ }^{2}$ Comenius University in Bratislava, Department of Social Work, Slovakia.

${ }^{3}$ Faculty of Healthcare, Alexander Dubcek University of Trencin, Slovakia

\section{E-mail address:}

aondrusova@gmail.com

\section{Reprint address:}

Adriana Ondrusova

Trnava University in Trnava

Faculty of Health Care and Social Work

Trnava

Slovakia

Source: Clinical Social Work and Health Intervention

Volume: 12

Pages: $44-53$

Cited references: 18

\section{Reviewers:}

Andrea A Shahum

Chapel Hill NC, USA

Jarmila Holkova

Malindi

\section{Publisher:}

International Society of Applied Preventive Medicine i-gap

\section{Keywords:}

Anthropometric Measurements. Kenya. Malnutrition.

CSWHI 2021; 12(1): 44 - 53; DOI: 10.22359/cswhi_12_1_10 C C Clinical Social Work and Health Intervention

\section{Abstract:}

Introduction: Malnutrition remains an important public health challenge in developing countries. Approximately, each year, 3 million children below 5 years old die due to malnutrition. Evidence-based nutrition programs depend on accurate estimates of malnutrition derived from anthropometric data collected from nutrition centers for therapeutic feeding. Anthropometric information can be used to determine an individual's nutritional status and prevalence of malnutrition, and subsequently provide 
the essential medical and nutritional care for children as a part of the management of malnutrition. Aim of our study was to track progress of anthropometric measurements of malnourished children enrolled in therapeutic feeding programs from the point of admission up to a period of four months.

Methods: This was an observational cohort study or 7 months for 227 malnourished children admitted to the therapeutic feeding program in Kwale County, Kenya. Anthropometric measurements were taken at admission, $1^{\text {st }}, 2^{\text {nd }}, 3^{\text {rd }}$ and $4^{\text {th }}$ months in the program. Progress of WAZ, HAZ, MUAC and WHZ of malnourished children were later analysed using WHO AnthroPlus.

Results: At admission, $30 \%$ of children were at risk of malnutrition; $34 \%$ of children with moderate to acute stages of malnutrition; $36 \%$ of children suffering from severe acute malnutrition. In the course of the therapeutical feeding program, protein food supplements were provided to the child and family as such. This led to a decrease in prevalence of severe acute malnutrition of $19 \%$ after 4 months in the nutritional program. Progress in all anthropometric parameters after 4 months were reported, with these median values: WAZ $\mathrm{z}$-score (-2.81 to -1.15$)$; HAZ z-score (-2.35 to 1.00$)$; MUAC z-score (2.47 to -1.68$)$; WHZ z-score (-2.22 to -0.71$)$.

Conclusion: We conclude that anthropometric measurements of children significantly improves after four months of intensive therapeutic feeding of malnourished children. In this study the results indicate that comprehensive care for malnourished children, which includes: correct and accurate anthropometric measurements; providing treatment; regular monitoring of the children; collaboration with caretakers of the children, with health workers in the rural health facilities; with community health workers in communities lead to improved child nutrition.

Keywords: Malnutrition, Therapeutic feeding, Wasting, Stunting, Underweight, MUAC, Anthropometry.

\section{Introduction}

The World Food Program defines malnutrition as a state in which the physical function of an individual is impaired to the point where he or she can no longer maintain adequate bodily performance processes such as: growth; physical work; resisting or recovering from disease ${ }^{1}$. Malnutrition is a global health issue especially for children under 5 years of age who are in significantly higher risk of mortality and morbidity than well-nourished children ${ }^{2}$. Malnutrition, more specifically undernutrition, is a global health issue; it is one of the leading causes of morbidity and mortality among children below the age of 5 years. It contributes to at least $45 \%$ of mortalities in children below the age of 5 years ${ }^{3,4}$.

It is estimated that 50.5 million children under 5 years of age worldwide suffered from acute malnutrition; 150.8 million children under 5 are affected by chronic malnutrition; 20 million babies are born of low birth weight each year; 38.3 million children under 5 are overweight ${ }^{3,5}$. The majority of children under 5 years of age, who suffer from acute malnutrition, live in SubSaharan Africa and in South Asia ${ }^{6}$.

The need for better nutrition was recognized in the Sustainable Development Goal (SDG) 2, adopted by the UN in 2015 which aims to zero hunger and improve nutrition. This SDG provides global and national impetus to address malnutrition and expedite progress.

Acute and chronic malnutrition is measured and quantified through anthropometry, which is constituted by the basic data - age, sex, weight, height, length, edema, MUAC. Separate indices in most circumstances are constructed of weightfor-height, height-for-age and weight-for-age ${ }^{1}$. For statistical reasons, WHO recommends using the Z-scores (standard deviation scores), which means that measurements of a study population should be related to the reference population ${ }^{7}$. All these measurements are the key building blocks of anthropometrics and are essential for classifying nutritional status in children under 5 years of age $^{1}$.

In Kenya, malnutrition remains one of the most serious health issues among children under 5 years of age. Kenya has $26 \%$ of children under 5 with chronic malnutrition; $4 \%$ with acute malnutrition; $11 \%$ are underweight ${ }^{8}$. Kenya Demo- 
graphic and Health Survey further reports that infant mortality rate stands at 39 deaths per 1,000 live births, and a mortality rate of 52 deaths per 1,000 live births for children below the age of 5 years. At these levels, about one in every 26 Kenyan children dies before reaching age 1; about one in every 19 does not survive to his or her fifth birthday ${ }^{8}$. In regions where food security and natural disasters have affected the population, rates of acute malnutrition in under 5 are higher ${ }^{2}$.

According to the 2009 Kenya Demographic and Health Survey (KDHS), Coast Province, particularly Kwale County, one of the 47 Counties in Kenya, had a higher rate (39\%) of malnutrition among children under 5 years of age than the national average; the second highest in the country. The 2014 Kenya Demographic and Health Survey (KDHS) shows that this has reduced over the years and was reported to be at $29.7 \%$ but was still the second highest in the country ${ }^{9}$. To improve health status of malnourished children under 5, Trnava University from Slovak Republic, established 3 nutrition centers in selected areas within Kwale County, because of the highest rate of malnutrition in children under 5 years of age and also the second factor of areas selection was the logistical location of the centers due to accessibility from the surrounding communities.

Nutrition Centers, were established in Matuga Sub-county in Kwale County, were housed at Kwale Sub-county Hospital, Mkongani Health Center and Tiwi Rural Health Training Center in 2012. These provide medical, social and counselling services for malnourished children and their caretakers, through the diagnostic and treatment of malnutrition, provision of adequate complementary food (porridge, vitamin supplements, beans) as well as education of caretakers on child care and their health contribute to improving quality of life of their families and communities as a whole. Community Management of Acute Malnutrition (CMAM) as a proven approach to manage acute malnutrition in children under five ${ }^{10}$, we implemented in our therapeutic feeding programs in Kwale Region. We trained 50 community health volunteers to do community-based mobilization, screening, follow-up, counselling and education, which increases coverage, access, and effectiveness of treatment for acute malnutrition.

The objective of our study is to describe fac- tors putting a child in higher risk of being malnourished; to find prevalence of moderate and severe acute malnutrition at admission and then after 4 months in the nutritional program; mainly to follow progress of anthropometric parameters when a child and family are supported by protein food supplements and checked regularly.

\section{Methods}

\section{Study groups}

In 2012, Trnava University from the Republic of Slovakia, through cooperation with the Ministry of Health, Kenya, established 3 nutrition centers for therapeutic feeding in Kwale County, Kenya. The mission of the three nutrition centers was to provide nutrition care to malnourished children aged between 6 and 59 months. The nutrition care provided included: weekly growth monitoring; promotion and provision of therapeutic diets; supplementation of vitamin A and minerals; support group for pregnant and lactating mothers. Medical care, in partnership with local hospitals, was also provided to malnourished children. Medical care included treating of illnesses associated with malnutrition, deworming and immunization.

The 3 feeding centers had 2 nutrition programs: a) Supplementary Feeding Program (SFP) for children who were moderately malnourished; b) Outpatient Therapeutic Feeding Programs (OTP) for the severely malnourished children.

Moderately malnourished children enrolled in the SFP were provided every fortnight with $3.5 \mathrm{~kg}$ of Corn Soy Blend (CSB) porridge or sachets of Plumpy soy and their anthropometric measurements taken for purpose of monitoring their growth on every visit to the center. Children who were admitted into the SFP were those who had a MUAC between 11.5-12.4 cm, and/or with a Weight for Height Z (WHZ) score <-2 SD to > -3 SD. Moderately malnourished children would be discharged from the SFP once their MUAC was greater than $12.5 \mathrm{~cm}$ or their WHZ was greater than -2 SD for 2 consecutive visits, or had defaulted from the program for more than 3 consecutive visits.

Severely malnourished children who were enrolled in the OTP were provided with Ready to Use Therapeutic Food (RUTF), for our program we used Plumpy nuts which were provided to the 
severely malnourished on a weekly basis based on their weights. The minimum number of Plumpy nut sachets a child could be given per week was 11 to a maximum of 35 sachets. Each Plumpy nut sachet provided 500 kcals. In addition, the severely malnourished children were also provided with clinical care, where their underlying illnesses were promptly treated. Admission criteria into OTP were based on MUAC < $11.5 \mathrm{~cm}$, were older than 6 months, or their WHZ was <-3 SD, had bilateral pitting edema Grade 1 or/and had poor appetites. Children who could not eat more than half sachet of Plumpy nut were considered to be having poor appetite and were referred for inpatient care. They were discharged from the program as cured once their MUAC was greater than $11.5 \mathrm{~cm}$ or their WHZ was $-2 \mathrm{SD}$ and had no pitting edema for 2 consecutive visits. They would also be discharged from OTP as defaulters when they failed to attend their appointments for 3 consecutive visits. Severely malnourished children once discharged from OTP would automatically be admitted into SFP.

\section{Data collection}

Data for the research was collected through a screening program in the 3 feeding centers, conducted between September 2019 to March 2020. A total of 994 children were screened for malnutrition within that period. For the purpose of our research a total of 277 children were admitted into the study after excluding those who were returnee defaulters and, were younger than 6 months or were older than 59 months. The rest of the children who were well nourished and were not admitted into the study were asked to be attending growth monitoring sessions every 3 months for a period of one year.

\section{Data analysis}

Socio-demographic data of the respondents were collected from their parents/guardians by use of admission entry forms. Anthropometric measurements of the respondents were taken by trained health care workers, in accordance with the Integrated Management of Acute Malnutrition Guideline Handbook ${ }^{2}$, on each visit to the center. Anthropometric parameters were computed from WHO Child Growth Standards ${ }^{11}$ and using WHO AnthroPlus software. For each patient, we calculated their z-score of anthropometric parameters.
Z-score is a classification system to present child nutrition status with no bias due to age of a child.

The following anthropometric parameters were assessed using z-score values:

- weight- WAZ (weight-for-age z-score)...underweight evaluation

- height- HAZ (height for-age z-score)... stunting evaluation

- mid-upper arm circumference- MUAC (MUAC z-score)

- weight-height ratio- WHZ (weight-for-height $\mathrm{z}$-score).... malnutrition evaluation

According to the $\mathrm{WHO}^{11}$, there are these stages of malnutrition based on WHZ z-score:

- optimal nutrition status $>-1$ SD $<1 S D$,

- being at risk of acute malnutrition $>-2$ SD $<-1$ SD,

- moderate acute malnutrition $>-3 \mathrm{SD}<-2 \mathrm{SD}$,

- severe acute malnutrition <- $3 \mathrm{SD}$

when SD is a measure of distance between the child's value and the expected value of the reference population ${ }^{2}$.

In all anthropometric parameters, we followed medians of z-score with interquartile range values. We assessed changes in the values of $\mathrm{z}$ scores on monthly basis - at admission to the program, $1^{\text {st }}, 2^{\text {nd }}, 3^{\text {rd }}$ and $4^{\text {th }}$ months. Kruskal-Wallis test was used to find statistically significant difference in medians of z-scores. We followed the proportion of children with severe malnutrition on a monthly basis by McNemar's test which was used to compare paired proportions before and after an intervention. The level of significance was set to p-value less than 0.05 in statistical software R program 3.4.3 2017.

All data were collected in accordance with the Declaration of Helsinki and international ethical codex.

\section{Results}

The study group consisted of 277 malnourished children (Figure 1); 43\% male and 57\% female. The mean age was 15 months at admission. When following possible factors putting a child into higher risk of malnutrition, we found that $20 \%$ were born of low birthweight; $38 \%$ malnourished children came from a family with 5 and more children; $46 \%$ were with poor family income (less than $1 \$$ per a day per a capita only from casual sources). 
Figure 1: Basic characteristic of children admitted to therapeutic feeding program, $n=277$.

\begin{tabular}{|l|l|}
\hline Sex & $43 \%(118)$ \\
\hline Male & $57 \%(159)$ \\
\hline Female & $15.00 \pm 8.86$ month \\
\hline Age & 12.00 month \\
\hline Mean & 6.00 - 51 month \\
\hline Median & $2.83 \pm 0.55 \mathrm{~kg}$ \\
\hline Range & $2.80 \mathrm{~kg}$ \\
\hline Birthweight & $1.50-4.28 \mathrm{~kg}$ \\
\hline Mean & $80 \%(221)$ \\
\hline Median & $20 \%(56)$ \\
\hline Range & $46 \%(127)$ \\
\hline normal birthweight & $40 \%(112)$ \\
\hline low birthweight & $14 \%(38)$ \\
\hline Household income status per capita \\
\hline poor & \begin{tabular}{l}
$|l|$ \\
\hline Low
\end{tabular} \\
\hline regular income & $46 \%(127)$ \\
\hline Number of children in family \\
\hline 2 children and below & $17 \%(46)$ \\
\hline $3-5$ children & $38 \%(104)$ \\
\hline 5 and more children & \multicolumn{2}{|l|}{} \\
\hline
\end{tabular}

After screening, 64\% children were admitted to the Supplementary Feeding Program with 1 check-up within 14 days; $36 \%$ were admitted to the Outpatient Therapeutic Program with medical check-up needed once in 7 days. RUTF appetite test was done at admission because it is an important indicator of the clinical status of a child. Children who fail the RUTF test mean that they have lost their appetite and can only be managed well in inpatient care. In our study, 19\% of children failed this test and therefore were referred to the sub-county hospital with a therapeutic feeding unit for 7 days. Bilateral pitting edema is a sign of Kwashiorkor, a nutritional disorder caused by inadequate intake of proteins through diets. Edema was present in a total of 67 children; specifically edema grade 1 in 18\%; edema grade 2 in $6 \%$.

Underweight, stunting, wasting and MUAC are essential indicators of children's nutritional status. In our study, we analyzed these indicators by Weight for Age Z Scores (WAZ); Height for Age $\mathrm{Z}$ score (HAZ); MUAC and Weight for Height Z scores (WHZ).

Underweight is a result of multifactorial origin which includes inadequate intake of diet; recurring acute and chronic illnesses with also socio-economic family determinants. Median of WAZ z-score for evaluation of underweight was -2.81 with a range from -5.00 to 1.66 at admission time to our study group.

Stunting is a result of prolonged insufficient nutrition intake and recurring acute infections. In our study at admission time, median of $\mathrm{HAZ}$ zscore was -2.37 with range -5.10 to 1.48 .

MUAC measurements and its cut off points are useful in identifying malnourished children who need urgent treatment due to their elevated risk of dying. Especially it is useful in a community screening and also in a health facility with limited access to equipment and resources. In our study, the mean MUAC was $11.75 \mathrm{~cm}$ with minimum value $7.00 \mathrm{~cm}$ and maximum value $11.10 \mathrm{~cm}$. Median of MUAC z-score was at level -2.47 with a range -4.30 to -0.23 .

Wasting is caused by acute food shortage and chronic illness. It is used in predicting child mortality. In our study, the median WHZ z-score was -2.22 with a range -4.80 to 1.86 . Based on the WHZ z-score classification, in our study there were no children with optimal weight; $30 \%$ were at risk of acute malnutrition; $34 \%$ suffered from moderate acute malnutrition; $36 \%$ by severe acute malnutrition at the time of their admission into the three nutrition center (Figure2).

Figure 2: Anthropometric parameters of children at admission to therapeutic feeding program, $n=277$.

\begin{tabular}{|l|l|}
\hline \multicolumn{2}{|l|}{ Type of nutrition care } \\
\hline SFP & $64 \%(176)$ \\
\hline OTP & $36 \%(101)$ \\
\hline RUTF appetite test \\
\hline+ pass & $81 \%(224)$ \\
\hline - fail & $19 \%(53)$ \\
\hline Presence of bilateral pitting edema \\
\hline No & $76 \%(210)$ \\
\hline body edema + & $18 \%(49)$ \\
\hline body edema ++ & $6 \%(18)$ \\
\hline
\end{tabular}




\begin{tabular}{|c|c|}
\hline \multicolumn{2}{|l|}{ Weight } \\
\hline mean & $7.05 \pm 2.06 \mathrm{~kg}$ \\
\hline median & $6.90 \mathrm{~kg}$ \\
\hline range & $2.80-13.47 \mathrm{~kg}$ \\
\hline \multicolumn{2}{|l|}{ WAZ z-score } \\
\hline Median & -2.81 \\
\hline Range & $-5.00 / 1.66$ \\
\hline \multicolumn{2}{|l|}{ Height } \\
\hline mean & $78.06 \pm 10.42 \mathrm{~cm}$ \\
\hline median & $76.00 \mathrm{~cm}$ \\
\hline range & $63.80-97.47 \mathrm{~cm}$ \\
\hline \multicolumn{2}{|l|}{ HAZ z-score } \\
\hline Median & -2.37 \\
\hline Range & $-5.10 / 1.48$ \\
\hline \multicolumn{2}{|l|}{ MUAC } \\
\hline mean & $10.08 \pm 1.07 \mathrm{~cm}$ \\
\hline median & $10.90 \mathrm{~cm}$ \\
\hline range & $8.50-11.50 \mathrm{~cm}$ \\
\hline \multicolumn{2}{|l|}{ MUAC z-score } \\
\hline Median & -2.47 \\
\hline Range & $-4.30 /-0.23$ \\
\hline \multicolumn{2}{|l|}{ Weight for height } \\
\hline optimal weight & $0 \%(0)$ \\
\hline $\begin{array}{l}\text { being at risk of acute } \\
\text { malnutrition }\end{array}$ & $30 \%(83)$ \\
\hline $\begin{array}{l}\text { moderate acute } \\
\text { malnutrition }\end{array}$ & $34 \%(93)$ \\
\hline $\begin{array}{l}\text { severe acute } \\
\text { malnutrition }\end{array}$ & $36 \%(101)$ \\
\hline \multicolumn{2}{|l|}{ WHZ z-score } \\
\hline Median & -2.22 \\
\hline Range & $-4.80 / 1.86$ \\
\hline
\end{tabular}

We further examined the medians and interquartile ranges of the anthropometric scores of the children from the time they were admitted into the feeding programs up to period of 4 months.

When comparing median values, we found through the Kruskal-Wallis test (Figure3) the following significant differences:

i) there was a statistically significant change in WAZ z-score from admission (median -2.81) to value in $1^{\text {st }}$ month (median -2.14) and also another significant change from $3^{\text {rd }}$ month (median -1.63) to $4^{\text {th }}$ month (median -1.15).

ii) in evaluation of the HAZ z-score, we found significant progress from $1^{\text {st }}$ month value (median -2.13) to $2^{\text {nd }}$ month value (median 1.72 ) and also the progress from $3^{\text {rd }}$ month value (median -1.42 ) to $4^{\text {th }}$ month value (median -1.00).

iii) there was a statistically significant difference of the MUAC $\mathrm{z}$-score median from $1^{\text {st }}$ month $(-2.23)$ to $2^{\text {nd }}$ month $(-1.94)$.

iv) value of the WHZ $\mathrm{Z}$-score significantly change from $1^{\text {st }}$ month (median -1.95) to $2^{\text {nd }}$ month (median -1.48) and $3^{\text {rd }}$ month (median $-1.16)$.

Figure 4 graphically presents progress of anthropometric medians up to the $4^{\text {th }}$ month since the time of admission. Median value of $\mathrm{WHZ} \mathrm{z}_{\mathrm{z}}$ score progressed from -2.22 at admission to -0.71 on the $4^{\text {th }}$ month, which means WHZ changed from moderate acute malnutrition to optimal nutrition status of the 277 respondents in our study. In HAZ z-score, stunting, a progress of median was observed from -2.37 at the point of admission to -1.00 on the $4^{\text {th }}$ month. Medians of WAZ $\mathrm{z}$-score, reflecting underweight, and MUAC zscore changed from -2.81 and -2.47 at admission to -1.15 and -1.68 after 4 -months period.

On monthly basis, we followed proportion of children in the program with median value of WHZ z-score worse than -3. At admission, there were $36 \%$ children with severe acute malnutrition. By using McNemar's test, we found out a significant difference in proportion of children with severe malnutrition at $3^{\text {rd }}$ month, a decrease from $27 \%$ to $23 \%$ and on the $4^{\text {th }}$ month, decrease to $19 \%$ (Figure 5).

\section{Discussion}

Aim of this study was to examine the progression of anthropometric measurements of malnourished children after their admission into the 3 nutrition centers in Kwale County, Kenya. In 2012, the 3 nutrition centers opened their doors for malnourished children, but for purpose of this study, we collected our data from September 2019 to March 2020. In this study, we examined factors that predisposed children to malnutrition in our study location and found that the majority of respondents were: born of low birthweight (20\%); came from families with poor income less than $1 \$$ per a day per a capita only from ca- 
Figure 3: Progress in medians and IOR of anthropometric parameters of children after 4 months in the nutritional program, $n=277$.

\begin{tabular}{|c|c|c|c|c|c|c|}
\hline & Admission & 1st month & 2nd month & 3rd month & 4th month & p-value \\
\hline \multirow{2}{*}{$\begin{array}{l}\text { WAZ } \\
\text { z-score }\end{array}$} & -2.81 & $-2.14^{*}$ & -1.98 & -1.63 & $-1.15^{*}$ & \multirow[t]{2}{*}{0.008} \\
\hline & $-3.75 /-2.23$ & $-2.91 /-1.47$ & $-2.68 /-1.58$ & $-1.97 /-1.28$ & $-1.82 /-0.91$ & \\
\hline \multirow{2}{*}{$\begin{array}{l}\text { HAZ } \\
\text { z-score }\end{array}$} & -2.37 & -2.13 & $-1.72^{*}$ & -1.42 & $-1.00^{*}$ & \multirow[t]{2}{*}{0.013} \\
\hline & $-3.22 /-1.68$ & $-3.11 /-1.65$ & $-2.18 /-1.24$ & $-2.23 /-1.03$ & $-1.69 /-0.42$ & \\
\hline \multirow{2}{*}{$\begin{array}{l}\text { MUAC } \\
\text { z-score }\end{array}$} & -2.47 & -2.23 & $-1.94^{*}$ & -1.82 & -1.68 & \multirow[t]{2}{*}{0.042} \\
\hline & $-3.16 /-1.80$ & $-2.99 /-1.70$ & $-2.55 /-1.46$ & $-2.03 /-1.52$ & $-1.97 /-1.41$ & \\
\hline \multirow{2}{*}{$\begin{array}{l}\text { WHZ } \\
\text { z-score }\end{array}$} & -2.22 & -1.95 & $-1.48^{*}$ & $-1.16^{*}$ & -0.71 & \multirow[t]{2}{*}{0.031} \\
\hline & $-2.78 /-1.46$ & $-2.55 /-1.35$ & $-2.38 /-1.01$ & $-1.80 /-0.83$ & $-1.66 /-0.38$ & \\
\hline
\end{tabular}

${ }^{*}$ Indicating statistically significant difference (p 0.05) of given mean comparing to mean in the previous month by using Kruskal-Wallis test.

Figure 4: Progress in medians of anthropometric parameters of children after 4 months in the nutritional program, $n=277$.

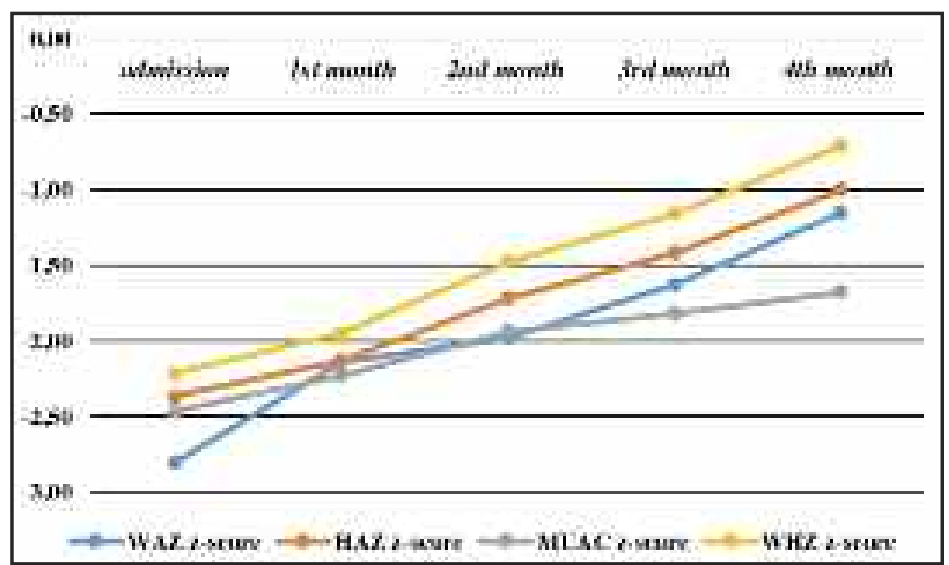

chronic malnutrition, comorbidities and leading into high child mortality ${ }^{13}$.

Socio-economic status of a family is another important determinant of a child nutritional status due to ability of family to provide adequate food intake. Research conducted in Ghana with the objective of finding significant predictors of wasting, stunting and underweight observed that, $63.1 \%$ of malnourished preschool children who were suffering from malnutrition came from families with low sual sources (46\%); family having 3-5 children (46\%). Sengupta-Philip-Benjamin found in their study that $19 \%$ of malnourished cases were born of low birthweight, which was a significant predictor of malnutrition of children under 5 years ${ }^{12}$. According to the WHO, 15-20\% of all births worldwide are of low birthweights. Low birthweight is associated significantly with acute and monthly income ${ }^{14}$. In complex treatment of child malnutrition, it is essential to cover food needs of a child and the whole family. Size of the household is another risk factor that causes malnutrition. The risk of developing malnutrition increases with every additional member to the household. Asfaw et al. (2015) found that almost $60 \%$ of malnourished children below the age of

Figure5: Progress of severe malnutrition proportion cases in children after 4 months in the nutritional program, $\mathrm{n}=277$.

\begin{tabular}{|l|c|c|c|c|c|}
\hline & Admission & 1st Month & 2nd Month & 3rd Month & 4th Month \\
\hline $\begin{array}{l}\text { Severe } \\
\text { malnutrition } \\
\text { WHZ z-score >-3 }\end{array}$ & $36 \%(101)$ & $32 \%(88)$ & $27 \%(77)$ & $23 \%(63)$ & $19 \%(52)$ \\
\hline p-value & & 0.367 & 0.236 & 0.041 & 0.031 \\
\hline
\end{tabular}


5 came from families with 3-5 children who suffered from acute food insecurity even during harvest time ${ }^{15}$.

Weight for Age z-score, denoted by WAZ zscore, is a major indicator of underweight in children. In this study, we observed a statistically significant progress ( $p$-value 0.008 ) in median of WAZ z-score from the point of admission at 2.81 , to -2.14 after the $1^{\text {st }}$ month of treatment and eventually to -1.15 by the end of the $4^{\text {th }}$ month. In 2014, KDHS reported WAZ z-score mean value -0.8 for Kwale County ${ }^{8}$. This difference signifies an increased underweight among children under the age of 5 years in Kwale County between the time the survey was released in 2014 and 2020 when we did this study. This increase can be attributed to acute or chronic illness of children as well as to socio-economic conditions that affect families in Kwale County.

Over the period of this study, the proportion of the HAZ z-score dropped with a p-value 0.013 from -2.37 at admission to -1.00 after 4 months of treatment. Ali et al. identified in his study similar values of the HAZ $\mathrm{z}$-score of mean $\pm \mathrm{SD}$ value $-1.33 \pm 1.2$. There was significant progress (p-value 0.026) of the HAZ z-score after introducing complementary food in nutrition program $^{14}$. MUAC is an important anthropometric tool for assessing nutritional status of children and can be used as a standalone tool for monitoring nutritional recovery ${ }^{16}$. In this study we observed the median of the MUAC z-score progress from the value of -2.47 to -1.68 after 4 months of malnutrition management. The mean of the MUAC z-score in a study realized in Burkina Faso by Goossenes et al. (2012) decreased from -3.3 at the admission to -1.5 at discharging ${ }^{17}$. The most significant change in our study occurred in the WHZ z-score from median value at admission -2.22 to -0.71 after $4^{\text {th }}$ month of nutritional care (p-value 0.031). This finding is similar with study in Burkina Faso (admission mean value 3.4 to discharge mean value -1.5$)^{17}$. This may be due to expected better feeding and childcare practices by educated mothers and caretakers.

Comparison of the mentioned studies with our study pointed out the differences mainly in the MUAC z-score and the WHZ z-score. It can be explained especially by the time mothers introduce complementary foods; types of food for children under 5 included into the nutrition pro- gram; feeding practice of malnourished children; household food insecurity; proper childcare; quality of health care services available to children.

In our study, we found a significant decrease in the prevalence of children suffering from severe acute malnutrition at the admission (101, $36 \%$ ) compared to the prevalence after 4 months in a nutritional care program $(52,19 \%)$. This decrease was statistically significant by McNemar's test (p-value 0.031). Tadesse et al. compared the prevalence of severe acute malnutrition at admission $(28.1 \%)$ and after 4 weeks in nutritional program $(21.6 \%)$. Children with the lowest WHZ (WHZ $<-3$ ) showed a significant change on the average weight gain after 4 weeks of therapy. The largest response was observed among the severely malnourished children ${ }^{18}$. The reason for this significant improvement was due to provision of adequate food supplement in accordance with national guidelines; prompt referral to the hospital in case of emergency; comprehensive community work. We thus conclude that anthropometric measurements of children significantly improve after four months of intensive therapeutic feeding of malnourished children.

There are some limits in our study. First, we did not consider children's comorbidities such as HIV, malaria, diarrhea or tuberculosis on a nutrition status for research intent even though as a part of medical services, we were aware of a child's health status. Second, we did not take into account correlation of rainy season or harvest time which significantly influence food intake in a family. As a third and main limit, 3 nutrition centers have been established within rural health facilities with good infrastructure (geographically easily reachable places for delivery of food supplements from national and international storages). Therefore, our results cannot be interpreted in the same or similar way in less developed regions of Kenya.

\section{Conclusion}

This study concludes that malnourished children below 5 years show significant improvement in their nutritional status when they are admitted into therapeutic feeding programs for a period of at least four months. This improvement corresponds with a proven approach of integrated management of malnutrition where there are interventions at the national/regional level (available health 
center and nutrition center with educated and skilled experts); interventions at community level (for caretakers, family members and communities to provide health and nutrition education, promotion of optimal infant-feeding practices and better childcare); systematic organization of work in a nutrition center (accurate anthropometry measurements, adequate supplementary food for malnourished children under 5as RUTF, porridge, vitamins but also support food for families during child's treatment); home visiting and monitoring of children in their home environment; regular assessment of child nutrition status and creation of the networking among professionals working with malnourished children to share knowledge and experiences and to collaborate if needed. All mentioned areas of intervention are an integral part of comprehensive care approach to successfully treat malnutrition of children under five.

\section{References}

1. WFP \& CDC (2005) A Manual: Measuring and Interpreting Malnutrition and Mortality. Available online: https://www.unscn.org/en/ resource-center/archive/methods-tools-andindicators?idnews $=1473$ (accessed on 2 July, 2020).

2. MINISTRY OF MEDICAL SERVICES \& MINISTRY OF PUBLIC HEALTH AND SANITATION (2010) Handbook Integrated Management of Acute Malnutrition. Kenya: UNICEF.

3. GLOBAL NUTRITION REPORT (2018) Available online: https://globalnutritionreport.org/reports/global-nutrition-report-2018 (accessed 2 July, 2020).

4. DELACEY E et al. (2020) The nutritional status of children living within institutionalized care: a systematic review. In: Peer J, DOI 10.7717/peerj.8484.

5. MORAMARCO S et al. (2018) Filling the Gaps for Enhancing the Effectiveness of Community-Based Programs Combining Treatment and Prevention of Child Malnutrition: Results from the Rainbow Project 20152017 in Zambia. In: International Journal of Environmental Research and Public Health. 2018 Sep; 15(9): 1807. doi: 10.3390/ijerph 15091807

6. UNICEF (2012) Evaluation of Integrated Management of Acute Malnutrition (IMAM).
Kenya Country Case Study. Available online: https://www.unicef.org/evaldatabase/files/Ke nya_CMAM_formatted.pdf (accessed 3 July 2020).

7. DE ONIS M (2000) Measuring nutritional status in relation to mortality. In: Bulletin of WHO, 2000; 78(10):1271-4.

8. KENYA DEMOGRAPHIC AND HEALTH SURVEY (2014) Available online: https:// dhsprogram.com/pubs/pdf/fr308/fr308.pdf (accessed 3 July 2020).

9. NDEMWA M et al. (2017) Nutritional status and association of demographic characteristics with malnutrition among children less than 24 months in Kwale County, Kenya. In: Pan Afr Med J. 2017 Nov 24;28:265. doi: 10.11604/pamj.2017.28.265.12703. eCollection 2017

10. UNICEF (2013) Global Evaluation of Community Management of Acute Malnutrition (CMAM): Global Synthesis Report (link is external). New York: UNICEF.

11. WHO (2006) WHO child growth standards: methods and development: length/height-forage, weight-for-age, weight-for-length, weight-for-height and body mass index-forage. Geneva. Available online: https://www. who.int/childgrowth/standards/technical_report/en/ (accessed 8 July 2020).

12. SENGUPTA P, PHILIP N, BENJAMIN AI (2010) Epidemiological correlates of undernutrition in under - 5 years children in an urban slum of Ludhiana. In: Health and Populations: Perspective and Issues. 2010 vol.33 (1), 1-9.

13. WHO (2014) Global Nutrition Targets 2025: Low birth weight policy brief. Available online: https://www.who.int/nutrition/publications/globaltargets2025_policybrief_lbw/en/ (accessed 20 July 2020).

14. ALI Z et al. (2017) The effect of maternal and child factors on stunting, wasting and underweight among preschool children in Northern Ghana. In: BMC Nutri. 2017; 3:31. Available online: https://www.ncbi.nlm.nih. gov/pmc/articles/PMC7050753/ (accessed 20 July 2020).

15. ASFAW M et al. (2015) Prevalence of undernutrition and associated factors among children aged between six to fifty-nine months in Bule Hora District South Ethiopia. In: BMC 
Public Health. 2015; 15:41. Available online: https://www.ncbi.nlm.nih.gov/pmc/articles/P MC4314803/ (accessed on 20 July 2020).

16. BURRELL A. et al. (2017) Monitoring and discharging children being treated for severe acute malnutrition using mid-upper arm circumference: secondary data analysis from rural Gambia. In: Int Health. 2017 Jul; 9(4): 226-233. Available online: https://www.ncbi. nlm.nih.gov/pmc/articles/PMC5881269/ (accessed on 22 July 2020).

17. GOOSSENES S et al. (2012) Mid-Upper Arm Circumference Based Nutrition Programming: Evidence for a New Approach in Regions with High Burden of Acute Malnutrition. In: PLoS One. 2012; 7(11): e49320. Available online: https://www.ncbi.nlm.nih. gov/pmc/articles/PMC3506602/ (accessed on 22 July 2020).

18. TADESSE A. W. et al. (2017) Choosing Anthropometric Indicators to Monitor the Response to Treatment for Severe Acute Malnutrition in Rural Southern Ethiopia-Empirical Evidence. In: Nutrients. 2017 Dec; 9(12): 1339. Available online: https://www.ncbi. nlm.nih.gov/pmc/articles/PMC5748789/ (accessed on 20 July 2020). 